\title{
Gender-Based Violence among Pregnant Women Consulting at the Antenatal Care Unit of the Bamenda Regional Hospital
}

\author{
Dobgima Walter Pisoh ${ }^{*}$, Samje Moses ${ }^{1}$, Berinyuy Zyh Akumawah1, Dohbit Julius Sama², \\ Ako Fidelis Atabon ${ }^{3}$, Pascal Foumane ${ }^{2}$ \\ ${ }^{1}$ Department of Clinical Sciences, Faculty of Health Sciences, University of Bamenda, Bambili, Cameroon \\ ${ }^{2}$ Department of Obstetrics and Gynaecology, Faculty of Medicine and Biomedical Sciences, University of Yaounde I, Yaounde, \\ Cameroon \\ ${ }^{3}$ Bamenda Regional Hospital, North West Region, Cameroon, Bamenda, Cameroon \\ Email: *dobpisoh@yahoo.co.uk
}

How to cite this paper: Pisoh, D.W. Moses, S., Akumawah, B.Z., Sama, D.J., Atabon, A.F. and Foumane, P. (2020) Gender-Based Violence among Pregnant Women Consulting at the Antenatal Care Unit of the Bamenda Regional Hospital. Open Journal of Obstetrics and Gynecology, 10, 1525-1543.

https://doi.org/10.4236/ojog.2020.10110138

Received: September 27, 2020

Accepted: November 10, 2020

Published: November 13, 2020

Copyright $\odot 2020$ by author(s) and Scientific Research Publishing Inc. This work is licensed under the Creative Commons Attribution International License (CC BY 4.0).

http://creativecommons.org/licenses/by/4.0/

\begin{abstract}
Background: Gender-based violence is violence against men and women in which the woman is more likely to be the victim. Globally, one in every four women is physically or sexually abused during pregnancy. The main objective was to study gender-based violence among pregnant women attending antenatal care at the Bamenda Regional Hospital (BRH). Methods: We carried out a hospital-based cross-sectional study among 231 pregnant women at the antenatal care unit of the BRH from January to March 2018. The study included all women who gave a written informed consent. A questionnaire adapted from the WHO multi-country study was used to collect data on sociodemographic characteristics, aspects of gender-based violence (GBV), and data for other associated factors were collected by face-to-face interview. Data were analysed using SPSS version 23.0. Chi-square test and Fisher exact test were used to compare frequencies. Student $t$-test was used to compare means. Binary logistic regression analysis and multivariate analysis were used to eliminate confounders. The level of statistical significance was set at $\mathrm{p}<0.05$. Results: A total of $56.3 \%(n=130)$ of pregnant women involved in the study were found to be survivors of GBV. Psychological trauma, physical assault and sexual violence were found in $47.2 \%, 30.2 \%$ and $19.9 \%$ respectively. Depression and anxiety were the most frequent clinical manifestations. Only $37.7 \%$ of the survivors sought management. The factors statistically associated with the occurrence of GBV were: for physical violence a partner that smokes; for sexual violence a history of sexual assault on the survivor as a child, a primary level of education of the partner, and a partner that is alco-
\end{abstract}


holic; for psychological violence a history of sexual assault on the survivor as a child, a primary level of education of the partner, and a partner that is alcoholic. After adjusting for confounders, having a partner with only a primary education had a statistically significant association [3.610 (1.431 - 9.091), $\mathrm{p}$ $=0.007$ ] with the occurrence of GBV. Conclusion: GBV is a key health risk among pregnant women consulting at the ANC unit of the Bamenda Regional Hospital and proper education of the partner is primordial in its prevention.

\section{Keywords}

Gender-Based Violence, Prevalence, Associated Factors

\section{Background}

Gender-based violence (GBV) is violence involving men and women, in which females are usually the victims, and which is derived from unequal power relationships between men and women. Violence is directed specifically against a woman because she is a woman or affects women disproportionately [1]. GBV is generally understood to include physical (i.e. pushing, kicking, throwing objects, hitting with hands or objects, choking, attacking with a knife or blade), sexual (i.e. forced sexual relations), and psychological (i.e. insults, belittlement, threats to or threat of abandonment) abuse from intimate partners, sexual violence by non-partners, sexual abuse of girls, and acts such as trafficking women for sex [2]. As GBV remains one of the most rigorous challenges to women's health and well-being, it is one of the indispensable issues regarding equity and social justice [2]. The causes of gender-based violence are multidimensional including social, economic, cultural, political, and religious [2] [3].

Pregnancy and childbirth are times of unique vulnerability to violent victimization because of changes in women's physical, social, emotional, and economic needs during pregnancy [4]. Violence during pregnancy escalates during a woman's gestation with serious consequences not only for the woman, but also for the foetus and ultimately for the child's development. Extreme stress and anxiety provoked by violence during pregnancy may reduce women's ability to obtain nutrition, rest, exercise, and medical care [5]. This is the reason why the WHO recommends the clinical evaluation of partner violence during prenatal consultations to reach the objective of a positive pregnancy experience for all women. Some adverse effects include foetal death, low birth weight, preterm delivery, small for gestational age, maternal mortality, mental health problems, kidney infections, reduced weight gain during pregnancy, and increased likelihood of undergoing operative delivery in pregnant women [2]. Similarly, violence during pregnancy is associated with spontaneous abortion, bleeding during pregnancy and higher neonatal deaths [6].

Globally, one woman in every four is physically or sexually abused during 
pregnancy, usually by her partner [7]. A study carried out in Nepal in 2012 showed that $33 \%$ of women suffered from GBV [8]. Another study conducted by Sunjay et al. in Nepal in 2016 showed a prevalence of GBV among pregnant women to be at 91.1\% [9]. Makayoto et al. in Kenya reported the prevalence of GBV among pregnant women to be $37 \%$ [10]. A survey done in Cameroon reported the prevalence of GBV [physical violence] among women to be $53 \%$, with $11 \%$ of them occurring during pregnancy [1].

Little is known about GBV among pregnant women and the factors that could be associated with its occurrence in Cameroon. We had as aim to determine the prevalence and factors associated with GBV among pregnant women consulting at the antenatal clinic of the Bamenda Regional Hospital (BRH).

\section{Methods}

This was a hospital-based cross-sectional study carried out at the Antenatal Care Unit of the BRH, Cameroon from the $5^{\text {th }}$ of January to the $5^{\text {th }}$ of March 2018. The BRH is a referral hospital in the North-West Region of the country, serving a population of about $1,728,953$ inhabitants. The antenatal consultation unit receives clients from the North-West Region and neighbouring Regions of different ethnic groups. We included all pregnant women consulting at the Antenatal Unit of the BRH during the study period and who gave their consent to participate in the study. Using the Cochrane's formula and a prevalence (p) of $15.23 \%$ [11], the minimum sample size needed was 198 pregnant women.

Ethical clearance was obtained from the Institutional Review Board of the Faculty of Health Sciences, University of Bamenda and administrative authorisations were obtained from the Regional Delegation of Public Health for the North West Region and the Director of the BRH.

Participants were approached at the ANC unit upon arrival, and the study was explained to them in detail. Using a convenience sampling method, all interested participants who read and signed the consent form were consecutively enrolled into the study and those who were not literate placed thumbprints after accepting to have fully understood the study. All eligible participants underwent a face-to-face interview using the language preferred by the participant and data was collected using an interviewer administered pre-tested, structured questionnaire, adapted from a WHO multi-country study [12].

The study variables included: 7 questions on specific acts of physical violence (slaps, pushing, hit with a fist, kicked, dragged, burnt, and gun or knife used on her), 4 questions on psychological violence (insults, humiliated in front of others, intimidated on purpose, threatened to be hurt) and 3 questions on sexual violence (physically forced to have sexual intercourse, sexual intercourse because she was afraid of being hurt by the spouse and forced to do a humiliating or degrading sexual act); sociodemographic characteristics (age in years, gravidity, marital status, family structure, level of education, occupation); survivors history (sexual history, HIV status and experience of sexual assault as a child); clinical manifestations such as bruises, abdominal pain, headaches, sprains, depression 
and anxiety (depression and anxiety were studied using the Hospital Anxiety and Depression Scale [13] and participants with a score of $>8$ were considered as having symptoms of depression or anxiety); management (pharmacological or non-pharmacological); the sociodemographic characteristics of their partners; and experience of violence by the participant's mother.

Data were entered into an electronic database on CS Pro version 7.1 and analysis was done with SPSS version 23.0. Chi-square or Fischer's exact test was used to compare proportions while differences in means were compared using the student's $t$-test. The odds ratio (OR) with a 95\% confidence interval [95\% CI] was used to summarize the strength of association between the variables and GBV. The level of statistical significance for the study was set at $p<0.05$. Binary logistic regression and multivariate analysis were used to eliminate confounders.

\section{Results}

A total of 260 pregnant women were approached from which 240 gave their consent to participate in the study. From these 240 pregnant women, 231 provided complete information and were enrolled in the study. The mean age of the participants was 26 years with extremes of 16 years and 44 years. Most (66.2\%) $(\mathrm{n}=153)$ were multigravida, $71.4 \%(\mathrm{n}=165)$ were married either traditionally or legally, $51.1 \%(\mathrm{n}=118)$ were employed and $45.0 \%(\mathrm{n}=104)$ had attained university education (Table 1). For each sociodemographic variable, GBV survivors represented more than $50 \%$ of the population of each category except for the age group $30-39$ years (48.5\%).

Table 1. The sociodemographic characteristics of the participants and GBV survivors.

\begin{tabular}{|c|c|c|c|c|c|c|}
\hline \multirow[b]{2}{*}{ Variable } & \multirow[b]{2}{*}{ Category } & \multicolumn{2}{|c|}{ Sample population } & \multicolumn{2}{|c|}{ GBV SURVIVORS } & \multirow{2}{*}{$\begin{array}{l}\text { Percentage of GBV } \\
\text { survivor in each } \\
\text { category [\%] }\end{array}$} \\
\hline & & $\begin{array}{l}\text { Number } \\
(\mathrm{n}=231)\end{array}$ & $\begin{array}{c}\text { Percentage } \\
{[\%]}\end{array}$ & $\mathrm{n}=130$ & $\begin{array}{c}\text { Percentage } \\
(\%)\end{array}$ & \\
\hline \multirow{4}{*}{$\begin{array}{l}\text { Age groups } \\
\text { (in years) }\end{array}$} & $10-19$ & 20 & 8.7 & 14 & 10.8 & 70.0 \\
\hline & $20-29$ & 141 & 61.0 & 81 & 62.3 & 57.4 \\
\hline & $30-39$ & 66 & 28.6 & 32 & 24.6 & 48.5 \\
\hline & $40-49$ & 4 & 1.7 & 3 & 2.3 & 75.0 \\
\hline \multirow{2}{*}{ Gravidity } & Primigravida & 78 & 33.8 & 40 & 30.8 & 51.3 \\
\hline & Multigravida & 153 & 66.2 & 90 & 69.2 & 58.8 \\
\hline \multirow{3}{*}{$\begin{array}{l}\text { Marital } \\
\text { status }\end{array}$} & Single & 40 & 17.3 & 23 & 17.7 & 57.5 \\
\hline & Cohabiting & 26 & 11.3 & 14 & 10.8 & 53.8 \\
\hline & Married & 165 & 71.4 & 93 & 71.5 & 56.4 \\
\hline \multirow{2}{*}{ Occupation } & Unemployed & 113 & 48.9 & 64 & 49.2 & 56.6 \\
\hline & Employed & 118 & 51.1 & 66 & 50.8 & 55.9 \\
\hline \multirow{4}{*}{$\begin{array}{c}\text { Educational } \\
\text { level }\end{array}$} & None & 4 & 1.8 & 3 & 2.3 & 75.0 \\
\hline & Primary & 31 & 13.4 & 17 & 13.1 & 54.8 \\
\hline & Secondary & 92 & 39.8 & 55 & 42.3 & 59.8 \\
\hline & University & 104 & 45.0 & 55 & 42.3 & 52.9 \\
\hline
\end{tabular}


The prevalence of GBV was $56.3 \%(\mathrm{n}=130)$. The prevalence of the different types of violence were: $47.2 \%(\mathrm{n}=109)$ for psychological violence, $30.3 \%(\mathrm{n}=$ 70) for physical violence and $19.9 \%(\mathrm{n}=46)$ for sexual violence. Among the GBV survivors, some of these pregnant women presented with two types of violence, with psychological and physical violence being the most frequent at 28.5\% $(n=37)$, while $15.4 \%(n=20)$ presented with all three types of violence (Table 2). The perpetrator of GBV was a partner in $76.2 \%(n=99)$ of cases.

The most represented sociodemographic variables as concerns the survivors of GBV were; the age group $20-29$ years at $62.3 \%(\mathrm{n}=81)$, multigravida at $69.2 \%(n=90)$, married women at $71.5 \%(n=93)$, employed at $50.8 \%(n=66)$ and both secondary and university level of education at $42.3 \%(n=55)$ each.

The principal symptoms described were both borderline depression and borderline anxiety in $18.5 \%(\mathrm{n}=24)$ of cases each. The other symptoms were abdominal pain in $16.9 \%(\mathrm{n}=22)$, bruises in $15.4 \%(\mathrm{n}=20)$, anxiety in $12.3 \%(\mathrm{n}=$ 16), headaches in $11.5 \%(\mathrm{n}=15)$, depression in $3.8 \%(\mathrm{n}=5)$, and sprains in $3.1 \%$ $(n=4)$ of the survivors.

Eighty-one (62.3\%) of the survivors of GBV received no management. Of the 49 (37.7\%) survivors who were managed, 23 (46.9\%) received medications (pharmacological management) and 26 (53.1\%) were managed with non-pharmacologic means. There was no statistical significance between the sociodemographic factors of the survivor and the occurrence of any type of GBV (Table 3).

Table 2. The characteristics of gender-based violence.

\begin{tabular}{ccc}
\hline GBV & Frequency $(\mathbf{n})$ & Percentage (\%) \\
\hline Experience of GBV $(\mathbf{n}=\mathbf{2 3 1})$ & 130 & 56.3 \\
Yes & 101 & 43.7 \\
No & & \\
Prevalence of each type of GBV $(\mathbf{n}=\mathbf{2 3 1})$ & 70 & 30.3 \\
Physical & 109 & 47.2 \\
Psychological & 46 & 19.9 \\
Sexual & & \\
Categories of GBV (n = 130) & 10 & 7.7 \\
Physical violence only & 37 & 28.5 \\
Psychological only & 8 & 6.2 \\
Sexual violence only & 37 & 28.5 \\
Physical + psychological & 3 & 2.3 \\
Physical + sexual & 15 & 11.5 \\
Psychological + sexual & 20 & 15.4 \\
Physical + psychological + sexual & & \\
Perpetrator of GBV (n = 130) & & 28.3 \\
Intimate partner & 99 & 76.2 \\
Non-partner & 28 & 21.5 \\
Both intimate and non-partners & 3 & 2.3 \\
\hline
\end{tabular}


Table 3. Association between sociodemographic factors and presence of GBV.

\begin{tabular}{cccccc}
\hline \multirow{2}{*}{ Variable } & Category & $\begin{array}{c}\text { Presence } \\
\text { of violence }\end{array}$ & $\begin{array}{c}\text { Physical } \\
\text { violence }\end{array}$ & $\begin{array}{c}\text { Psychological } \\
\text { violence }\end{array}$ & $\begin{array}{c}\text { Sexual } \\
\text { violence }\end{array}$ \\
\cline { 3 - 6 } Age groups (years) & $10-19$ & 0.195 & 0.135 & 0.792 & 0.077 \\
& $20-29$ & 0.654 & 0.505 & 0.349 & 0.086 \\
& $30-39$ & 0.131 & 0.113 & 0.134 & 0.755 \\
Gravidity & $40-49$ & 0.631 & 1.000 & 0.346 & 0.178 \\
& Primigravida & 0.275 & 0.201 & 0.289 & 0.853 \\
& Multigravida & 1.091 & 0.272 & & \\
Marital status & Single & 0.864 & 0.740 & 0.965 & 0.674 \\
& Cohabiting & 0.791 & 0.612 & 0.760 & 0.256 \\
& Married & 0.967 & 0.526 & 0.803 & 0.256 \\
Occupation & Employment & 0.914 & 0.224 & 0.858 & 0.622 \\
& No employment & 0.914 & & & \\
& None & 0.634 & 0.587 & 0.261 & 0.129 \\
& Primary & 0.862 & 0.869 & 0.808 & 0.064 \\
Educational level & Secondary & 0.382 & 0.228 & 0.303 & 0.914 \\
& University & 0.347 & 0.194 & 0.281 & 0.119 \\
\hline
\end{tabular}

On the survivors' history, $25.4 \%(\mathrm{n}=33)$ had a history of sexual assault as a child; $14.6 \%(n=19)$ had a positive history of violence on the mother, and $4.6 \%$ $(n=6)$ were HIV seropositive. The victim's history and partner characteristics that were statistically associated with more frequent occurrence of GBV were; a history of sexual assault on the survivor as a child [2.784 (1.328 - 5.835), p = 0.005 ], the age group $20-29$ years [ $1.9(1.07-3.37), \mathrm{p}=0.027$ ] and a primary level of education of the partner [3.52 (1.46-8.46), $\mathrm{p}=0.03$ ] as seen on Table 4 .

The only factor that was statistically associated with more frequent occurrence of physical violence among pregnant women was a partner that smokes [3.25 (1.16 -9.1), $\mathrm{p}=0.026$ ] as seen on Table 5 .

The factors that were statistically associated with more frequent occurrence of sexual violence were; a history of sexual assault on the survivor as a child [4.5 (2.19 - 9.28), $\mathrm{p}<0.001$ ]; a primary level of education of the partner [4.23 (1.94 $9.2), \mathrm{p}<0.001]$; and a partner that is alcoholic [2.12 $(0.99-4.51), \mathrm{p}=0.048]$ as seen on Table 6.

The factors that were statistically associated with more frequent occurrence of psychological violence were: a history of sexual assault on the survivor as a child [2.93 (1.46 - 5.89), $\mathrm{p}=0.002$ ]; a primary level of education of the partner [ 2.69 (1.25 - 5.84), $\mathrm{p}=0.01]$; and a partner that is alcoholic $[2.35(1.17-4.7), \mathrm{p}=$ 0.014 ] as seen on Table 7 .

After adjusting for confounders, there was a statistically significant association between partners who had achieved only a primary education and the presence of GBV among pregnant women [3.610 (1.431 - 9.091), p $=0.007$ ] as seen on Table 8 . 
Table 4. Association between victim's history, partner characteristic and GBV.

\begin{tabular}{|c|c|c|c|c|c|}
\hline \multirow{2}{*}{\multicolumn{2}{|c|}{ Variable }} & \multicolumn{2}{|c|}{ Presence of violence (n/\%) } & \multirow{2}{*}{ Odds ratio (CI 95\%) } & \multirow{2}{*}{$P$ value } \\
\hline & & Yes $(n=130)$ & No $(n=101)$ & & \\
\hline \multicolumn{2}{|c|}{$\begin{array}{l}\text { History of sexual assault on } \\
\text { victim as a child }\end{array}$} & $33(25.4)$ & $11(10.9)$ & $2.784(1.328-5.835)$ & 0.005 \\
\hline \multicolumn{2}{|c|}{$\begin{array}{l}\text { Experience of violence by } \\
\text { participant's mother }\end{array}$} & $19(14.6)$ & $12(11.9)$ & $0.023(0.015-1.236)$ & 0.167 \\
\hline \multicolumn{2}{|c|}{ Presence of HIV } & $6(4.6)$ & $6(6.0)$ & $0.766(0.240-2.451)$ & 0.653 \\
\hline \multirow[t]{7}{*}{ Age of partner (years) } & $10-19$ & $1(0.8)$ & $0(0.0)$ & I & 1.000 \\
\hline & $20-29$ & $50(38.5)$ & $25(24.8)$ & $1.9(1.07-3.37)$ & 0.027 \\
\hline & $30-39$ & $55(42.3)$ & $60(59.4)$ & $0.5(0.3-0.85)$ & 0.010 \\
\hline & $40-49$ & $22(16.9)$ & $13(12.9)$ & $1.38(0.66-2.9)$ & 0.394 \\
\hline & $50-59$ & $2(1.5)$ & $2(1.9)$ & $0.77(0.12-5.59)$ & 1.000 \\
\hline & $60-69$ & $0(0.0)$ & $1(0.9)$ & I & 0.438 \\
\hline & Female older & $1(0.8)$ & $2(1.9)$ & $0.38(0.03-4.29)$ & 0.582 \\
\hline \multirow{5}{*}{$\begin{array}{c}\text { Age difference } \\
\text { between spouses } \\
\text { (years) }\end{array}$} & $<2$ & $24(18.5)$ & $14(13.9)$ & $1.41(0.69-2.88)$ & 0.350 \\
\hline & $3-5$ & $46(35.4)$ & $40(39.6)$ & $0.84(0.48-1.42)$ & 0.511 \\
\hline & $6-10$ & $40(30.8)$ & $34(33.7)$ & $0.88(0.5-1.53)$ & 0.640 \\
\hline & $>10$ & $19(14.6)$ & $11(10.9)$ & $1.4(0.63-3.09)$ & 0.404 \\
\hline & None & $1(0.8)$ & $0(0.0)$ & I & 1.000 \\
\hline \multirow{3}{*}{$\begin{array}{l}\text { Educational } \\
\text { level of partner }\end{array}$} & Primary & $27(20.8)$ & $7(6.9)$ & $3.52(1.46-8.46)$ & 0.003 \\
\hline & Secondary & $50(38.5)$ & $41(40.6)$ & $0.91(0.54-1.56)$ & 0.742 \\
\hline & University & $52(40.0)$ & $53(52.5)$ & $0.6(0.36-1.02)$ & 0.059 \\
\hline \multicolumn{2}{|c|}{ Smoking partner } & $11(8.5)$ & $5(5.0)$ & $0.02(0.02-1.24)$ & 0.297 \\
\hline \multicolumn{2}{|c|}{ Alcoholic partner } & $30(23.1)$ & $12(11.9)$ & $0.77(0.24-2.45)$ & 0.029 \\
\hline
\end{tabular}

Table 5. Associated factors and physical violence.

\begin{tabular}{|c|c|c|c|c|c|}
\hline \multirow{2}{*}{\multicolumn{2}{|c|}{ Variable }} & \multicolumn{2}{|c|}{ Physical violence (n/\%) } & \multirow{2}{*}{ Odds ratio (CI 95\%) } & \multirow{2}{*}{$P$ value } \\
\hline & & Yes $(\mathrm{N}=70)$ & No $(N=161)$ & & \\
\hline \multicolumn{2}{|c|}{$\begin{array}{l}\text { History of sexual assault on } \\
\text { victim as a child }\end{array}$} & $16(22.9)$ & $28(17.4)$ & $1.41(0.71-2.81)$ & 0.331 \\
\hline \multicolumn{2}{|c|}{$\begin{array}{l}\text { Experience of violence by } \\
\text { participant's mother }\end{array}$} & $11(15.7)$ & $20(12.4)$ & $1.31(0.59-2.91)$ & 0.500 \\
\hline \multicolumn{2}{|c|}{ Presence of HIV } & $3(4.3)$ & $9(5.6)$ & $0.76(0.19-2.88)$ & 0.682 \\
\hline \multirow{6}{*}{$\begin{array}{l}\text { Age of partner } \\
\text { (years) }\end{array}$} & $10-19$ & $1(1.4)$ & $0(0.0)$ & I & 0.303 \\
\hline & $20-29$ & $26(37.1)$ & $49(30.4)$ & $1.35(0.75-2.44)$ & 0.317 \\
\hline & $30-39$ & $32(45.7)$ & $83(51.5)$ & $0.79(0.45-1.39)$ & 0.415 \\
\hline & $40-49$ & $11(15.7)$ & $24(14.9)$ & $1.06(0.49-2.31)$ & 0.875 \\
\hline & $50-59$ & $0(0.0)$ & $4(2.5)$ & I & 0.317 \\
\hline & $60-69$ & $0(0.0)$ & $1(0.6)$ & l & 1.000 \\
\hline
\end{tabular}




\section{Continued}

\begin{tabular}{cccccc}
\hline & Female older & $1(1.4)$ & $2(1.2)$ & $1.15(0.1-12.91)$ & 1.000 \\
$\begin{array}{c}\text { Age difference } \\
\text { between spouses } \\
\text { (years) }\end{array}$ & $3-5$ & $25(35.7)$ & $61(37.9)$ & $0.91(0.51-1.63)$ & 0.753 \\
& $6-10$ & $21(30.0)$ & $53(32.9)$ & $0.87(0.48-1.6)$ & 0.662 \\
& $>10$ & $11(15.7)$ & $19(11.8)$ & $1.39(0.63-3.11)$ & 0.416 \\
& None & $1(1.4)$ & $0(0.0)$ & $/$ & 0.303 \\
$\begin{array}{c}\text { Educational } \\
\text { level of partner }\end{array}$ & Primary & $13(18.6)$ & $21(13.0)$ & $1.52(0.71-3.24)$ & 0.276 \\
& Secondary & $27(38.6)$ & $64(39.8)$ & $0.95(0.54-1.69)$ & 0.866 \\
& University & $29(41.4)$ & $76(47.2)$ & $0.79(0.45-1.39)$ & 0.418 \\
\multicolumn{2}{c}{ Smoking partner } & $9(12.9)$ & $7(4.3)$ & $3.25(1.16-9.1)$ & 0.026 \\
\multicolumn{2}{c}{ Alcoholic partner } & $18(25.7)$ & $24(14.9)$ & $1.98(0.99-3.94)$ & 0.050 \\
\hline
\end{tabular}

Table 6. Associated factors and sexual violence.

\begin{tabular}{|c|c|c|c|c|c|}
\hline \multirow{2}{*}{\multicolumn{2}{|c|}{ Variable }} & \multicolumn{2}{|c|}{ Sexual violence $(\mathrm{n} / \%)$} & \multirow{2}{*}{ Odds ratio (CI 95\%) } & \multirow{2}{*}{$P$ value } \\
\hline & & Yes $(\mathrm{N}=46)$ & No $(\mathrm{N}=185)$ & & \\
\hline \multicolumn{2}{|c|}{$\begin{array}{l}\text { History of sexual assault on } \\
\text { victim as a child }\end{array}$} & $19(41.3)$ & $25(13.5)$ & $4.5(2.19-9.28)$ & $<0.001$ \\
\hline \multicolumn{2}{|c|}{$\begin{array}{l}\text { Experience of violence by } \\
\text { participant's mother }\end{array}$} & $6(13.0)$ & $25(13.5)$ & $0.96(0.35-2.49)$ & 0.933 \\
\hline \multicolumn{2}{|c|}{ Presence of HIV } & $5(10.9)$ & $7(3.8)$ & $3.10(0.94-10.26)$ & 0.063 \\
\hline \multirow{7}{*}{$\begin{array}{l}\text { Age of partner } \\
\text { (years) }\end{array}$} & $10-19$ & $1(2.2)$ & 0 & l & 0.199 \\
\hline & $20-29$ & $16(34.8))$ & 59 & $1.14(0.58-2.25)$ & 0.708 \\
\hline & $30-39$ & $18(39.1)$ & 97 & $0.58(0.3-1.13)$ & 0.106 \\
\hline & $40-49$ & $10(21.7)$ & 25 & $1.78(0.79-4.03)$ & 0.164 \\
\hline & $50-59$ & $1(2.2)$ & 3 & $1.35(0.14-13.27)$ & 1.000 \\
\hline & $60-69$ & $0(0.0)$ & 1 & l & 1.000 \\
\hline & Female older & $1(2.2)$ & $2(1.1)$ & $2.03(0.18-22.92)$ & 0.488 \\
\hline \multirow{3}{*}{$\begin{array}{c}\text { Age difference } \\
\text { between spouses } \\
\text { (years) }\end{array}$} & $<2$ & $7(15.2)$ & $31(16.8)$ & $0.89(0.37-2.18)$ & 0.801 \\
\hline & $3-5$ & $19(41.3)$ & $67(36.2)$ & $1.24(0.64-2.4)$ & 0.523 \\
\hline & $6-10$ & $13(28.3)$ & $61(33.0)$ & $0.8(0.39-1.63)$ & 0.540 \\
\hline \multirow{5}{*}{$\begin{array}{c}\text { Educational } \\
\text { level of partner }\end{array}$} & $>10$ & $6(13.0)$ & $24(12.9)$ & $1.0(0.39-2.63)$ & 0.990 \\
\hline & None & $1(2.2)$ & $0(0.0)$ & l & 0.199 \\
\hline & Primary & $15(32.6)$ & $19(10.3)$ & $4.23(1.94-9.2)$ & $<0.001$ \\
\hline & Secondary & $17(36.9)$ & $74(40.0)$ & $0.88(0.45-1.71)$ & 0.705 \\
\hline & University & $13(28.3)$ & $92(49.7)$ & $0.39(0.19-0.81)$ & 0.009 \\
\hline \multicolumn{2}{|c|}{ Smoking partner } & $5(10.9)$ & $11(5.9)$ & $1.93(0.64-5.86)$ & 0.325 \\
\hline \multicolumn{2}{|c|}{ Alcoholic partner } & $13(28.3)$ & $29(15.7)$ & $2.12(0.99-4.51)$ & 0.048 \\
\hline
\end{tabular}


Table 7. Associated factors and psychological violence.

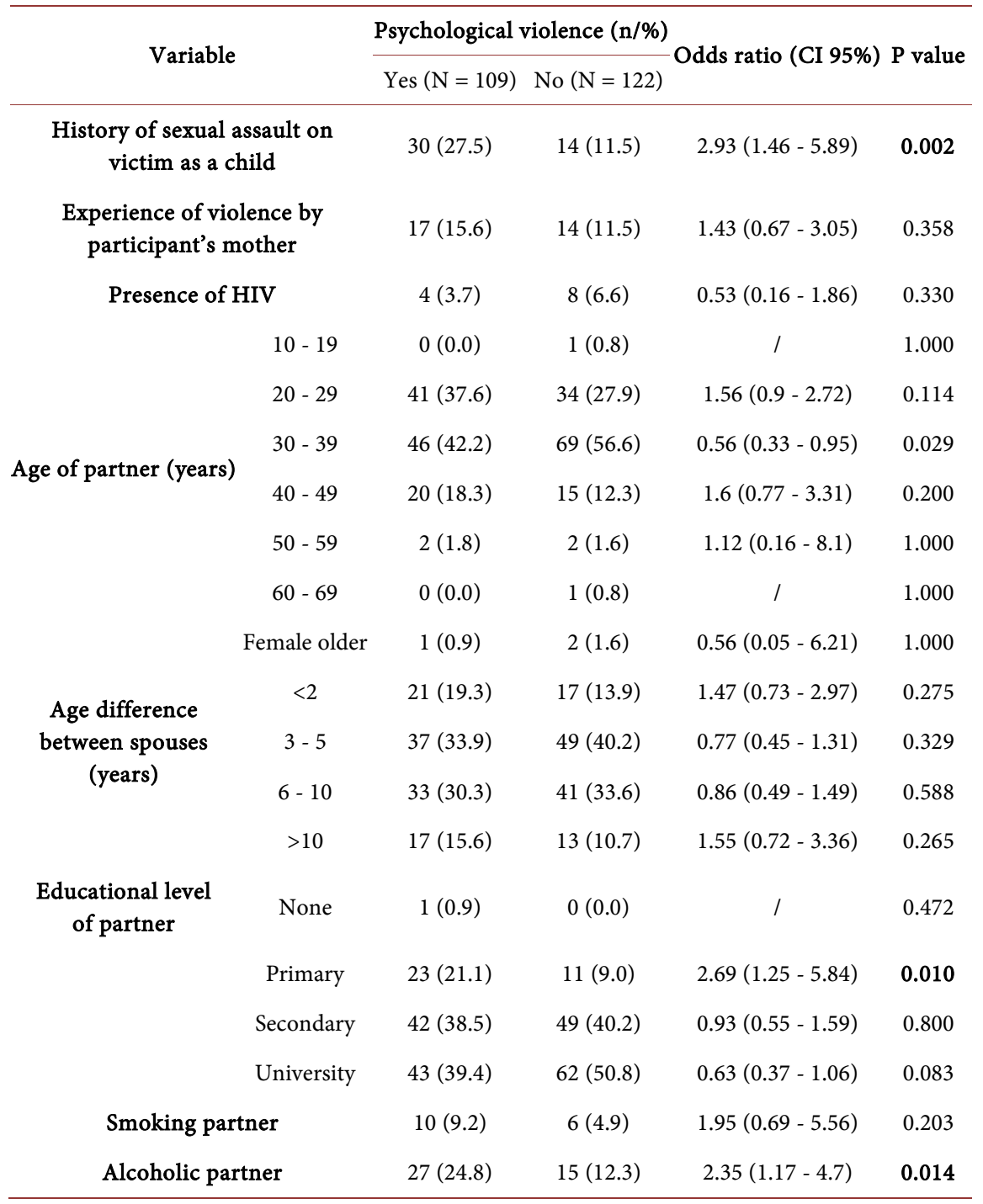

Table 8. Factors associated with gender-based violence (multivariate analysis).

\begin{tabular}{ccc}
\hline Variable & Adjusted OR (CI 95\%) & Adjusted P value \\
\hline Age participant 10 - 19 years & $0.603(0.202-1.796)$ & 0.363 \\
Level Education Partner (Primary) & $3.610(1.431-9.091)$ & 0.007 \\
Alcoholic partner & $0.531(0.239-1.182)$ & 0.161 \\
History sexual abuse on participant as child & $0.498(0.222-1.119)$ & 0.091 \\
Mother of participant experiencing violence & $0.884(0.380-2.056)$ & 0.774 \\
\hline
\end{tabular}

\section{Discussion}

\section{Sociodemographic characteristics of sample population}

The mean age of our sample population was 26 years which is close to the mean age of $26.6 \pm 6.5$ years of Idoko et al. in Gambia [14], 25 years of Dunkle et al. in South Africa [15] and 24 years reported by Makayato et al. in Kenya [10]. 
The similarity observed could be because more women tend to become pregnant around this age in sub-Saharan Africa. Married women were most represented (71.4\%) in our study which is similar to the findings of Makayato et al. [10] and Idoko et al. in [14] but differs from the study carried out by Dunkle et al. [15] who reported a majority of his study participants were cohabiting. However, pregnant women are more likely to be in relationships compared to non-pregnant populations. The most represented level of education in our study was at least a university education, which was higher when compared to $19 \%$ who had a university education in a study by Abebe et al. in Western Ethiopia [16]. This could be explained by the fact that our study was carried out in an urban area with many schools of higher education.

\section{The prevalence of GBV}

The prevalence of GBV reported in this study was $56.3 \%$ which is close to the prevalence of $43 \%$ reported by Oyedunni et al. [5] in Abuja, Nigeria, and that of $61 \%$ of intimate violence reported by Idoko et al. [14] in Gambia but higher than the $37 \%$ reported by Makayoto et al. in Kenya [10]. Our prevalence is lower than the $91.1 \%$ prevalence reported by Samjhana et al. in Nepal [17] who included aspects of verbal and economic violence that are not included in the WHO-adapted questionnaire used in our study. The differences in GBV prevalence could be explained by the diversity in the definitions of GBV in the various studies, which are culturally embedded. They can also be explained by differences in the types of violence that were studied and the differences in the populations sampled. In some of these studies, only intimate partner violence was considered. Thus, if regional prevalence values are to be determined and compared, then a standardized tool should be developed and used universally.

\section{Psychological violence}

Psychological violence was the most common type of violence in our study, with a prevalence of $47.2 \%$. This finding is similar to the findings of the studies done by Makayoto et al. in Kenya [10] of 29\%, the WHO multi-country study [12] by Idoko et al. in Gambia [14] of $60 \%$ and by Oyedunni et al. in Nigeria of $38.0 \%$ [5]. The higher prevalence of Idoko et al. [14] could be explained by the high verbal forms of intimate partner violence, which were the commonest forms. The prevalence of psychological intimate partner violence was $16.3 \%$ in the study by Abebe et al. [16] second to physical violence and was $8 \%$ in the study by Das et al. in Mumbai [18]. The differences observed could be due to differences in the perception of psychological violence in the various communities, as well as family influence when answering the questions, as was the case in the study in Mumbai.

\section{Physical violence}

The prevalence of physical violence in our study was $30.3 \%$ which is close to the prevalence of $29.2 \%$ reported by Abebe et al. [16] among pregnant women in Western Ethiopia and in the study by Oyedunni et al. in Nigeria where physical violence was the most represented at $36.4 \%$ [5]. The possible reason could be the presence of traditional norms that support beating women in the study area. 
This value is relatively higher when compared to $10 \%$ recorded by Makayoto et al. in Kenya [10]. Kenya is a patriarchal society where violence is recognized as one way of "disciplining" one's wife, with many women socialized to anticipate this discipline. Das et al. reported a prevalence of $12 \%$ in Mumbai [18]. In this study, the participants were interviewed in their homes with relatives intruding during interviews and maximum privacy could not be attained. The prevalence of physical violence in the study by Idoko et al. [14] in Gambia was above 55\%. This was probably influenced by the definitions used in these studies.

\section{Sexual violence}

Sexual violence was reported at $19.9 \%$ in our study which is close to $22 \%$ found by Idoko et al. in Gambia [14], but lower than that reported by Abebe et al. (30\%) which was the most common form of violence in his study, possibly due to sexual autonomy imbalance among the study areas. Our finding is higher than $12 \%$ found by Makayoto et al. in Kenya [10], and this can be explained by the fact that the educational level of participants in the study carried out in Western Ethiopia was lower than that in our study, as more than half of our study participants had at least a secondary level of education. These differences in literacy levels could have led to the disparity in results, as the more literate participants may have easily identified and reported cases of sexual violence. The prevalence of sexual violence was only $2 \%$ in the study by Das et al. in Mumbai [18] where relative influence could have biased the findings.

\section{Psychological, physical and sexual violence}

The most common types of violence in our study were psychological violence (28.5\%), and a combination of psychological and physical violence (28.5\%). Our observation is similar to those of Makayoto et al. in Kenya who recorded $49 \%$ of psychological abuse alone, followed by a combination of physical and psychological abuse at $14 \%$ [10]. In our study, $15.4 \%(n=20)$ of the participants presented with all three types of violence, which is higher than $4 \%$ found by Makayoto et al. [9].

\section{The perpetrator of gender-based violence}

The perpetrators of GBV were principally intimate partners in $76.2 \%(n=99)$ of cases which is close to $86.2 \%$ in the study by Abebe et al. [16] and $70.2 \%$ in the study by Oyedunni et al. [5] given that being a couple exposes the woman more to intimate partner violence.

\section{Clinical manifestations of gender-based violence}

The most frequent clinical manifestation seen in our study was the presence of borderline depression and borderline anxiety both at $18.5 \%$. Depressive and anxiety symptoms have been reported to be associated with GBV during pregnancy as seen in the study by Rodriguez et al. in a study among pregnant Latina women living in America [19], among pregnant women in Turkey by Karacam et al. [20], and by Nasreen et al. in Bangladesh [21]. GBV has been described as the single most important predictor of depression [22] and anxiety [23] in women.

\section{Management of gender-based violence}

More than half $(62.3 \%)$ of the survivors in our study received no form of 
management, and for those who sought treatment, $75 \%$ of this treatment were offered by non-medical personnel (friends and relatives). This is consistent with the observation of Idoko et al., where most of the women (59\%) did nothing about the abusive behaviour with $5 \%$ of them prevented from seeking health care [14]. Similarly, Das et al. reported that only $18 \%$ of GBV survivors in Mumbai sought clinical care for their injuries [18]. The high adherence to the idea that family matters should be discussed within the family may be the factor influencing the choice of seeking health care or not for the sake of family harmony.

\section{Factors associated with GBV}

\section{The age of the survivor}

The absence of financial autonomy at a young age is thought to be a source of GBV but not all studies have the same finding. The age group 20 - 29 years [1.9 (1.07 - 3.37), $\mathrm{p}=0.027$ ] was statistically associated with more frequent occurrence of GBV after univariate analysis but was not associated with GBV after multivariate analysis. This finding is similar to the finding of Makayoto et al. [10] and that of Samjhana et al. [17]. However, in the WHO multi-country study a young age was found to be a risk factor of GBV [24].

\section{Cohabitation and marriage}

Our study showed no statistically significant association between women who were cohabiting or married and the presence of GBV. However, some studies showed that there was more partner violence among women who were cohabiting rather than married [12] [24], with marriage being a protective factor. But Oladepo et al. found that married women were more likely to experience physical violence than single respondents [25].

HIV

HIV infection was not found to be a risk factor of GBV in our study. This finding was similar to the findings of Makayoto et al. [10] and in a study done in rural Rwanda [26].

\section{Education and employment}

The educational level of our participants was not associated with the occurrence of GBV. This is similar to the studies carried out in Kenya [10], and Mumbai [18]. Other studies, however, had shown that low level of education was a risk factor for experiencing abuse [27]. The WHO multi-country study found secondary education to be a protective factor [24] whereas Abebe et al. found that illiterate partners were $50 \%$ less likely to experience violence by their intimate partner during pregnancy [16]. Employment was not associated with the occurrence of GBV in our study although other studies had shown that being unemployed is a risk factor for experiencing abuse [27]. This is contrary to the finding that women who were employed were more likely to have reported intimate partner violence in the study by Das et al. in Mumbai [18].

\section{Assault as a child}

It is generally accepted that a history of assault as a child is a risk factor for 
future GBV. In this study, assault on the survivor as a child was statistically associated with more frequent occurrence of GBV [2.784 (1.328 - 5.835), $\mathrm{p}=$ 0.005 ] globally, as well as sexual [4.5 (2.19 - 9.28), $\mathrm{p}<0.001]$ and psychological violence [2.93 (1.46 - 5.89), $\mathrm{p}=0.002$ ] at univariate analysis but was not statistically associated with presence of violence after multivariate analysis. Other studies demonstrated strong evidence that a history of violence is significantly associated with intimate partner violence in pregnancy [12] [15].

\section{Age of the partner}

In our study, the age group of the partners was not statistically associated with the occurrence of GBV which is contrary to the finding of Oladepo et al. [25] who had the 20 - 29 years age group significantly associated with GBV. A possible explanation for these results could be that men in the younger age group are more violent.

\section{Education of the partner}

Primary level of education of the partner was statistically associated, at univariate analysis, with more frequent occurrence of GBV [3.52 (1.46 - 8.46), p = 0.03 ], psychological violence [ $2.69(1.25-5.84), \mathrm{p}=0.01]$ and sexual violence [4.23 (1.94 - 9.2), $\mathrm{p}<0.001]$, and after adjusting for confounders, having a partner with only a primary education was the only factor that was independently associated with gender-based violence [3.610 (1.431 - 9.091), $\mathrm{p}=0.007]$. This is similar to results got from a WHO multi-country study [12] which reported that partners who had attained a higher level of education were less likely to violate their pregnant partner and the finding of Hayati et al. [28] where sexual violence was associated with husbands educated less than 9 years.

\section{Alcohol and smoking}

After univariate analysis, a partner that is alcoholic was statistically associated with the occurrence of sexual violence $[2.12(0.99-4.51), \mathrm{p}=0.048]$ and psychological violence [2.35 (1.17 - 4.7), $\mathrm{p}=0.014$ ], but there was no statistically significant association after adjusting for confounders. This was consistent with studies by Hayati et al. [28], Idoko et al. [14], Makayoto et al. [10], Hindi et al. [29], Oyedunni et al. [5], Das et al. [18] and in the WHO Multi-country Study [24]. This contrasts with studies that have shown otherwise [27]. Field et al. [30] in a study carried out in Texas, USA reported the presence of aggressive behaviour following alcohol consumption. This aggressive behaviour places alcoholics at a greater chance of inflicting any form of violence.

The only factor that was statistically associated with more frequent occurrence of physical violence among pregnant women after univariate analysis was a partner that smokes [3.25 $(1.16-9.1, \mathrm{p}=0.026]$, but there was no association after adjusting for cofounders which is contrary to the findings in other studies [11] [14].

Study limitations: The main limitation of this study is that it was a hospital-based study and therefore, the data analysed herein does not include information from partners but rather relies solely on the reports of main respondents. 
Also, the sensitive nature of the subject matter makes underreporting a possible consideration.

\section{Conclusion}

Gender-based violence is a key health risk among pregnant women consulting at the ANC unit of the Bamenda Regional Hospital and proper education of the partner is primordial in its prevention. These high rates of GBV require more concerted efforts to identify, screen and facilitate care for affected women. The myth and silence that surround this practice have to be broken to permit appropriate interventions to be made.

\section{Acknowledgements}

We express our heartfelt thanks to participants for their willingness to participate in the study, without which this research would not be possible.

\section{Ethics Approval and Consent to Participate}

Ethical clearance was obtained from the Institutional Review Board of the Faculty of Health Sciences of the University of Bamenda and administrative authorisations were obtained from the Regional Delegation of Public Health for the North West Region and from the Director of the Bamenda Regional Hospital. Before administering the questionnaire, the study was explained to each participant in detail, and a written consent was obtained. Those who were not literate placed thumbprints after accepting to have fully understood the study.

\section{Availability of Data and Materials}

The datasets used and/or analysed during the current study are available from the corresponding author on a reasonable request.

\section{Funding}

This study did not receive any funding from any agency.

\section{Authors' Contributions}

DWP, SM BZA and FP were involved in the design of the study and drafted the protocol with input from other authors. DWP, SM BZA, FP, AAF analysed the data. DWP and BZA drafted and finalized the manuscript for publication. DSJ and AAF edited the manuscript. All authors contributed to the writing of the paper and approved the final version.

\section{Conflicts of Interest}

We, the authors, declare that we did not have competing interests.

\section{References}

[1] Population Reference Bureau (2010) Gender-Based Violence: Impediment to Re- 
productive Health.

www.igwg.org/igwg_media/gbv-impediment-to-RH.pdf

[2] Sanjel, S. (2013) Gender-Based Violence: A Crucial Challenge for Public Health. Kathmandu University Medical Journal, 11, 179-184.

https://doi.org/10.3126/kumj.v11i2.12499

[3] Duvvury, N., Callan, A., Carney, P. and Raghavendra, S. (2013) Intimate Partner Violence: Economic Costs and Implications for Growth and Development (English). The World Bank, Washington DC.

http://documents.worldbank.org/curated/en/412091468337843649/Intimate-partne r-violence-economic-costs-and-implications-for-growth-and-development

[4] Hajikhani, G.N., Hamzehgardeshi, Z., Hamzehgardeshi, L. and Shirzad, A.M. (2014) Sociodemographic Characteristics of Pregnant Women Exposed to Domestic Violence During Pregnancy in an Iranian Setting. Iranian Red Crescent Medical Journal, 16, e11989. https://doi.org/10.5812/ircmj.11989

[5] Arulogun, O.S. and Jidda, K.A. (2011) Experiences of Violence among Pregnant Women Attending Antenatal Clinics in Selected Hospitals in Abuja, Nigeria. Sierra Leone Journal of Biomedical Research, 3, 43-48. https://doi.org/10.4314/sljbr.v3i1.66650

[6] Silwal, P. (2012) Violence During Pregnancy among Young Married Women in Nepal. University of Connecticut, Storrs. http://digitalcommons.uconn.edu/gs_theses/264

[7] World Health Organization (2001) Global Programme on Evidence for Health Policy. Putting Women First: Ethical and Safety Recommendations for Research on Domestic Violence against Women. https://apps.who.int/iris/handle/10665/65893

[8] Office of the Prime Minister and Council of Ministers (2012) A Study on Gender Based Violence Conducted in Selected Rural Districts of Nepal. Government of Nepal, Kathmandu.

[9] Gurung, S. and Acharya, J. (2016) Gender-Based Violence among Pregnant Women of Syangja District, Nepal. Osong Public Health and Research Perspectives, 7, 101-107. https://doi.org/10.1016/j.phrp.2015.11.010

[10] Makayoto, L.A., Omolo, J., Kamweya, A.M., Harder, V.S. and Mutai, J. (2013) Prevalence and Associated Factors of Intimate Partner Violence among Pregnant Women Attending Kisumu District Hospital, Kenya. Maternal and Child Health Journal, 17, 441-447. https://doi.org/10.1007/s10995-012-1015-x

[11] Shamu, S., Abrahams, N., Temmerman, M., Musekiwa, A. and Zarowsky, C. (2011) A Systematic Review of African Studies on Intimate Partner Violence against Pregnant Women: Prevalence and Risk Factors. PLoS ONE, 6, e17591.

https://doi.org/10.1371/journal.pone.0017591

[12] Garcia-Moreno, C., Jansen, H.F.M., Ellsberg, M., Heise, L. and Watts, C.H. (2005) WHO Multi-Country Study on Women's Health and Domestic Violence against Women: Initial Results on Prevalence, Health Outcomes and Women's Resposnes. World Health Organization, Geneva.

[13] Zigmond, A.S. and Snaith, R.P. (1983) The Hospital Anxiety and Depression Scale. Acta Psychiatrica Scandinavica, 67, 361-370.

[14] Idoko, P., Ogbe, E., Jallow, O. and Ocheke, A. (2015) Burden of Intimate Partner Violence in the Gambia-A Cross Sectional Study of Pregnant Women. Reproductive Health, 12, Article No. 34. https://doi.org/10.1186/s12978-015-0023-x

[15] Dunkle, K.L., Jewkes, R.K., Brown, H.C., Yoshihama, M., Gray, G.E., McIntyre, J.A., et al. (2004) Prevalence and Patterns of Gender-Based Violence and Revictimization 
among Women Attending Antenatal Clinics in Soweto, South Africa. American Journal of Epidemiology, 160, 230-239. https://doi.org/10.1093/aje/kwh194

[16] Abebe Abate, B., Admassu Wossen, B. and Tilahun Degfie, T. (2016) Determinants of Intimate Partner Violence during Pregnancy among Married Women in Abay Chomen District, Western Ethiopia: A Community Based Cross Sectional Study. BMC Women's Health, 16, Article No. 6.

https://doi.org/10.1186/s12905-016-0294-6

[17] Gurung, S. and Acharya, J. (2015) Factor Influencing Gender Based Violence among Pregnant Women Attending Antenatal Clinic in PHC of Syangja District, Nepal. Makara Journal of Health Research, 19, 99-103.

https://doi.org/10.7454/mjhr.v19i3.5640

[18] Das, S., Bapat, U. and More, N. (2013) Intimate Partner Violence against Women during and after Pregnancy: A Cross-Sectional Study in Mumbai Slums. BMC Public Health, 13, Article No. 817. https://doi.org/10.1186/1471-2458-13-817

[19] Rodriguez, M.A., Heilemann, M.V., Fielder, E., Ang, A., Nevarez, F. and Mangione, C.M. (2008) Intimate Partner Violence, Depression, and PSTD among pregnant Latina women. The Annals of Family Medicine, 6, 44-52.

https://doi.org/10.1370/afm.743

[20] Karaçam, Z. and Ançel, G. (2009) Depression, Anxiety and Influencing Factors in Pregnancy: A Study in a Turkish Population. Midwifery, 25, 344-356. https://doi.org/10.1016/j.midw.2007.03.006

[21] Nasreen, H., Kabir, Z., Forsell, Y. and Edhborg, M. (2011) Prevalence and Associated Factors of Depressive and Anxiety Symptoms during Pregnancy: A population Based Study in Rural Bangladesh. BMC Women's Health, 11, Article No. 22. https://doi.org/10.1186/1472-6874-11-22

[22] Heise, L., Pitanguy, J. and Germain, A. (1994) Violence against Women: The Hidden Health Burden. World Bank Discussion Papers, 255.

[23] Karmaliani, R., Asad, N., Bann, C., Moss, N., Mcclure, E.M., Pasha, O., et al. (2009) Prevalence of Anxiety, Depression and Associated Factors among Pregnant Women of Hyderabad, Pakistan. International Journal of Social Psychiatry, 55, 414-424. https://doi.org/10.1177/0020764008094645

[24] Abramsky, T., Watts, C.H., Garcia-Moreno, C., Devries, K., Kiss, L., Ellsberg, M., et al. (2011) What Factors Are Associated with Recent Intimate Partner Violence? Findings from the WHO Multi-Country Study on Women's Health and Domestic Violence. BMC Public Health, 11, Article No. 109. https://doi.org/10.1186/1471-2458-11-109

[25] Oladepo, O., Yusuf, O.B. and Arulogun, O.S. (2011) Factors Influencing Gender Based Violence among Men and Women in Selected States in Nigeria. African Journal of Reproductive Health, 15, 78-86.

[26] Ntaganira, J., Muula, A.S., Siziya, S., Stoskopf, C. and Rudatsikira, E. (2009) Factors Associated with Intimate Partner Violence among Pregnant Rural Women in Rwanda. Rural Remote Health, 9, 1153.

[27] Testa, M., Quigley, B.M. and Leonard, K.E. (2003) Does Alcohol Make a Difference? Within Participants Comparison of Incidents of Partner Violence. Journal of Interpersonal Violence, 18, 735-743. https://doi.org/10.1177/0886260503253232

[28] Hayati, E.N., Högberg, U., Hakimi, M., Ellsberg, M.C. and Emmelin, M. (2011) Behind the Silence of Harmony: Risk Factors for Physical and Sexual Violence among Women in Rural Indonesia. BMC Women's Health, 11, Article No. 52. https://doi.org/10.1186/1472-6874-11-52 
[29] Hindin, M.J., Kishor, S. and Ansara, D.L. (2008) Intimate Partner Violence among Couples in 10 DHS Countries: Predictors and Health Outcomes. DHS Analytical Studies 18. United States Agency for International Development, Washington DC. http://dhsprogram.com/pubs/pdf/AS18/AS18.pdf

[30] Field, C.A., Caetano, R. and Nelson, S. (2004) Alcohol and Violence Related Cognitive Risk Factors Associated with the Perpetration of Intimate Partner Violence. Journal of Family Violence, 19, 249-254.

https://doi.org/10.1023/B:JOFV.0000032635.42145.66 


\section{Appendix}

\section{Questionnaire}

Instructions; Write the code (number) in the box e.g. If Yes, write 1

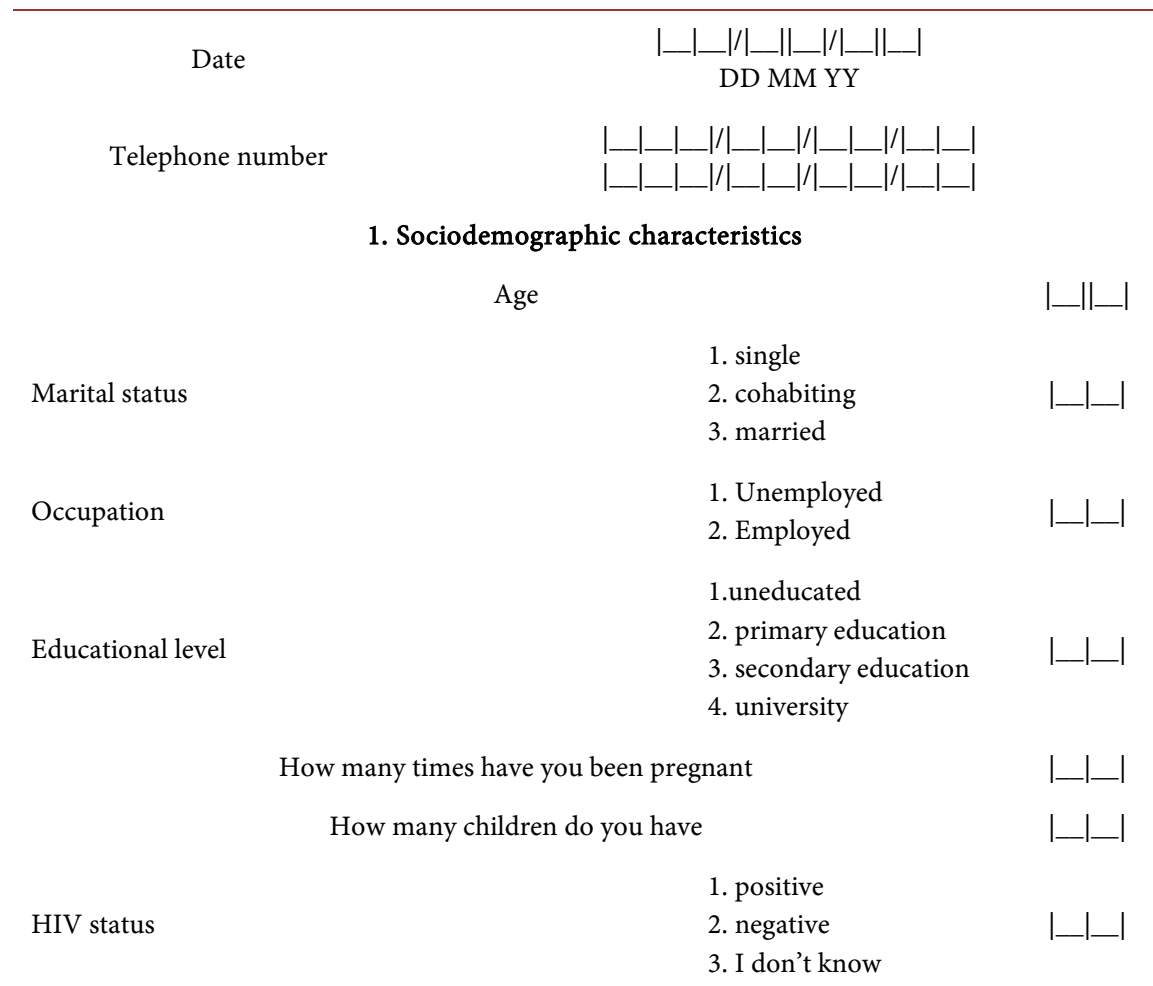

\section{Assessing gender-based violence}

2.1. Physical violence

Have you been slapped or thrown at something that can hurt you?

Have you been pushed or shoved?

Have you been hit with a fist or something else that could hurt?

Have you been kicked?

Have you been dragged or beaten up?

Have you been choked or burnt on purpose?

Have you had a gun, knife or other weapons used against you?
1. Yes

2. No

1. Yes

2. No

1. Yes

2. No

1. Yes

2. No

1. Yes

2. No

1. Yes

2. No

1. Yes

2. No

\subsection{Sexual violence}

Have you be physically forced to have sexual 1. Yes intercourse against your will?

2. No

Have you had sexual intercourse because you are afraid of what your partner might do?
1. Yes

2. No

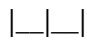

|_L

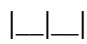

|___

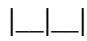

|_-_ |

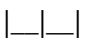




\section{Continued}

\begin{tabular}{ll}
\hline Have you been forced to do something sexual that & 1. Yes \\
you find degrading or humiliating? & 2 . No
\end{tabular}

\subsection{Psychological violence}

Have you been insulted or made to feel bad

1. Yes

about yourself?

2. No

Have you been humiliated or made to feel bad

1. Yes in front of others?

2. No

Have you been intimidated or scared on purpose

1. Yes

(for example by a partner yelling and smashing things)

2. No

Have you been threatened with harm

(directly or indirectly in the form of a threat to hurt

1. Yes

someone the respondent cares about).

2. No

\section{Assessing Risk factors}

Who carries out the violence

Educational level of partner

Does your partner smoke

Is your partner an alcoholic?

\section{Intimate partner}

2. Non-partner

Age of partner

1. uneducated

2. primary education

3. secondary education

4. university

1. Yes

2. No

1. Yes

2. No

Did you experience sexual assault as a child? Example

a) When you were a child, before you were 15 years of age, did a man ever touch you sexually or force you to touch him sexually when you didn't want to?

1. Yes

2. No

1. Yes

2. No

have sex when you did not want to?

1. Yes

Is your mother being violated by your father//or did your mother experience gender-based violence

2. No

3. I don't know

Thank you for your time.

\section{List of Abbreviations}

ANC: Antenatal Care

BRH: Bamenda Regional Hospital

GBV: Gender-Based Violence

HIV: Human Immuno-Deficiency Virus

WHO: World Health Organization 